\title{
Refractory lung metastasis from breast cancer treated with multidisciplinary therapy including an immunological approach.
}

\section{AUTHOR(S):}

Takada, Masahiro; Terunuma, Hiroshi; Deng, Xuewen; Dewan, Md Zahidunnabi; Saji, Shigehira; Kuroi, Katsumasa; Yamamoto, Naoki; Toi, Masakazu

\section{CITATION:}

Takada, Masahiro ...[et al]. Refractory lung metastasis from breast cancer treated with multidisciplinary therapy including an immunological approach.. Breast cancer (Tokyo, Japan) 2011, 18(1): 64-67

\section{ISSUE DATE:}

2011-01

URL:

http://hdl.handle.net/2433/138089

\section{RIGHT:}

The final publication is available at www.springerlink.com; This is not the published version. Please cite only the published version.; この論文 は出版社版でありません。引用の際には出版社版をご確認ご利用くだ さい。 
1 Refractory lung metastasis from breast cancer treated with multidisciplinary

2 therapy including an immunological approach

3

4 Masahiro Takada ${ }^{1}$, Hiroshi Terunuma ${ }^{2,3}$, Xuewen Deng ${ }^{2}$, Md. Zahidunnabi Dewan ${ }^{4}$,

5 Shigehira Saji ${ }^{5}$, Katsumasa Kuroi ${ }^{5}$, Naoki Yamamoto ${ }^{6,7}$, and Masakazu Toi ${ }^{1}$

6

7 1. Department of Breast Surgery, Graduate School of Medicine, Kyoto University

8 2. Biotherapy Institute of Japan

9 3. Tokyo Clinic Marunouchi Oazo

10 4. Department of Pathology, New York University Medical Center

5. Department of Surgery, Tokyo Metropolitan Cancer and Infectious Diseases Center Komagome Hospital

6. Department of Molecular Virology, Tokyo Medical and Dental University.

7. National Institute of Infectious Diseases

Correspondence: Masakazu Toi

Department of Breast Surgery, Graduate School of Medicine, Kyoto University,

54 Kawaracho, Shogoin, Sakyo-ku, Kyoto, 606-8507, JAPAN

Phone: +81-75-751-3660

Fax: +81-75-751-3616

toi@kuhp.kyoto-u.ac.jp

\section{This manuscript includes,}




\section{ABSTRACT}

2 A suggestive case of metastatic disease from breast cancer is reported. The

3 HER2-positive tumor was refractory to several agents, including anti-HER2 therapy,

4 trastuzumab and lapatinib. After re-induction of trastuzumab in combination with

5 activated natural killer cell injection therapy, tumor markers decreased, and finally a

6 synergistic effect of taxane and capecitabine showed treatment response. This case

7 suggests that multidisciplinary therapy including an immunological approach might be a

8 breakthrough to refractory disease.

9

\section{KEYWORDS}

11 breast cancer, metastasis, natural killer cell, chemotherapy, trastuzumab 
1

2

3

4

5

6

7

\section{Introduction}

Breast cancer can metastasize to lymph node, bone, lung, liver, and brain. Lung metastasis from breast cancer may not only decrease quality of life (QOL) but also threaten the patient's life. Therefore, it is important to control it.

Like endocrine therapy for estrogen-receptor (ER)-positive breast cancer, trastuzumab-based therapy is considered initially for tumors with overexpression of the HER-2/neu protein or amplification of the her-2/neu gene, which occur in 20-25\% of metastatic breast cancers [1]. Treatment with trastuzumab, a humanized mAb directed against the extracellular domain of HER2, resulted in a response rate of $21 \%$ in patients pretreated with chemotherapy, as a single agent. Trastuzumab also increased the clinical benefit of chemotherapy in metastatic breast cancer with HER2 overexpression [2].

Furthermore, adjuvant use of trastuzumab reduced recurrence remarkably in primary breast cancer [3-4].

The activity of trastuzumab was found to depend on the engagement of Fc-receptor-expressing lymphocytes, indicating antibody-dependent cellular cytotoxicity (ADCC) as the major mechanism of antibody action [5-7]. ADCC is triggered by interaction between antibody-coated target cells and Fc $\gamma$ RIII (CD16) on natural killer (NK) cells, which initiates a sequence of cellular events culminating in the 
1 release of cytotoxic, granzyme-containing granules [8,9]. Therefore, if we could

2 increase the activity of NK cells, the efficacy of treatment with trastuzumab could be

3 increased.

4 In this report, we present a case with refractory pulmonary metastasis, in which the

5 tumor was successfully treated with trastuzumab, taxane, capecitabine, and activated

$6 \quad$ NK cell injection therapy.

\section{$9 \quad$ Case Report}

10 A 55-year-old woman was treated in October 1999 for an invasive ductal carcinoma of

11 the right breast by mastectomy (Auchincloss's procedure) at another hospital.

12 Pathological examination showed pathological stage T2, positive lymph node for cancer

13 (11/22), lymphatic invasion, and negative for ER and progesterone receptor (PgR). She

14 was admitted to our hospital for adjuvant chemotherapy, which consisted of six courses

15 of cyclophosphamide, methotrexate, and 5-fluorouracil (CMF).

16 In August 2001, a chest CT scan performed as a follow-up study showed an abnormal

17 shadow in the lung, which was diagnosed as a metastatic carcinoma from the breast

18 cancer using transbronchial lung biopsy (TBLB). Because the tumor was positive for 
1 human epidermal growth factor receptor type 2 (HER2/neu) (3+ by an

2 immunohistochemical test), intravenous treatment with docetaxel and trastuzumab was

3 started. In January 2003, doxifluridine (5'DFUR) was added by oral administration, and

4 Response Evaluation Criteria in Solid Tumors (RECIST) indicated a partial tumor

5 response. In April 2004, we changed the treatment to capecitabine with trastuzumab

6 because of the tumor marker elevation. However, four months later, a chest CT scan

7 revealed that lung metastasis had progressed. Although four courses of epirubicin

8 monotherapy were started in September 2004, we could not stop disease progression. In

9 January 2005, the patient joined a clinical trial of lapatinib. Eleven months later, a

10 follow-up chest CT scan showed disease progression, and the patient subsequently

11 withdrew from the trial.

12 After multidisciplinary consultation and with the written consent of the patient, we

13 initiated therapy by injecting activated natural killer (NK) cells $[9,10]$. Blood was

14 collected, and peripheral blood mononuclear cells (PBMCs) were isolated from the

15 blood by Ficoll-Hypaque gradient centrifugation (Amersham Biosciences, Uppsala,

16 Sweden) and washed twice with RPMI 1640, and the number of cells was counted. To

17 generate activated NK cells, PBMCs were cultured in an anti-CD16-coated flask with

18 AIM-V (Invitrogen, Tokyo, Japan) medium supplemented with 5\% auto-plasma, 700 
1 U/ml IL-2 (Chiron, Amsterdam, Netherlands), and $1 \mu 1 / \mathrm{ml}$ OK432 (Chugai

2 Pharmaceutical, Tokyo, Japan) for $24 \mathrm{~h}$ at $39^{\circ} \mathrm{C}$. The cultured cells were then

3 centrifuged at $1000 \mathrm{rpm}$ for $10 \mathrm{~min}$, and the supernatant was discarded. Next, the cells

4 were again cultured in a flask (not coated with anti-CD16) in AIM-V medium

$5 \quad$ supplemented with $5 \%$ auto-plasma and $700 \mathrm{U} / \mathrm{ml} \mathrm{IL-2}$ at $37^{\circ} \mathrm{C}$ for 2 to 3 weeks. During

6 the culture periods, we added medium several times to expand and maintain the

7 population of the activated NK cells; the purity of the NK cells was 92 to $94 \%$. When

8 the activated NK cells were injected intravenously by drip ( $2 \times 10^{9}$ cells/injection), blood

9 was collected simultaneously. Then isolation and culture of NK cells were repeated at

10 two-week intervals.

11 We also measured cytotoxic activity of NK cells by the following method. Freshly isolated PBMCs and activated NK cells were tested for cytotoxic activity at various effector-to-target $(\mathrm{E} / \mathrm{T})$ ratios in a Calcein-AM release assay using TERASCAN VP

14 (Minerva Tech., Tokyo, Japan). We labeled the target cells, K562, with immunofluorescent-dye Calcein-AM solution (Do Jindo Lab., Kumamoto, Japan) and

16 incubated for $30 \mathrm{~min}$, washed the cells with PBS(-) and checked the fluorescence intensity of the cells. Target cells and effector cells were suspended with RPMI1640 and $10 \%$ fetal bovine serum at various E/T ratios and added into a 96-well plate, incubated 
1 for 2 hours and again checked for fluorescence intensity.

2 NK cell activity in the patient was extremely low before injection of activated NK

3 cells (Fig. 1); however, the activity increased after therapy began. Simultaneously, we

4 resumed intravenous treatment with trastuzumab. The concentrations of

5 carcinoembryonic antigen (CEA) and carbohydrate antigen 15-3 (CA15-3) had

6 decreased for six months, but began to increase following trastuzumab treatment. We

7 added capecitabine to trastuzumab; however, these tumor markers continued to increase.

8 At the same time, skin and bone metastases emerged. Therefore, weekly intravenous

9 injection of paclitaxel was added, and we also started hyperthermia for the skin

10 metastases. After that, NK cell activity increased again, and the tumor markers

11 decreased. A chest CT scan in November 2006 showed that the lung metastases had reduced (Fig. 1). NK cell activity remained at a high level and the progression-free survival was about 10 months.

Discussion

17 In the current report, lung metastasis which had been refractory to anti-HER2 therapy responded to the combination therapy of trastuzumab, capecitabine, paclitaxel, and 
1 activated NK cell injection therapy.

2 There are some reports that indicated a relation between the activity of NK cells and

3 disease progression. When breast cancer cells were inoculated into NOD/SCID mice

4 that possessed NK cell activity, only a small tumor grew at the inoculation site and no

$5 \quad$ organ metastasis was shown. However, when NOD/SCID $/ \gamma c^{\text {null }}$ (NOG) mice lacking

6 T-cell, B-cell, and NK cell activity were inoculated with breast cancer cells, there was

7 efficient formation of a relatively large tumor and spontaneous organ metastasis [10].

8 An epidemiological study demonstrated that the natural cytotoxic activity of PBMCs

9 was significantly associated with reduced cancer risk [11]. We recently reported that NK

10 cell activity in metastatic breast cancer patients was significantly reduced compared

11 with that of healthy controls [12]. Furthermore, several exploratory studies have shown

that NK cell therapy contributes to reduce the tumor burden in human cancers [13]. binding of Fc $\gamma$ RIII (CD16) to the Fc portion of the antibody, which initiates a sequence of cellular events culminating in the release of cytotoxic, granzyme-containing granules [8]. Trastuzumab is known to mediate ADCC against a HER2/neu-positive breast cancer target [5-7]. In the present case, after induction of activated NK cell injection therapy and trastuzumab, the NK cell activity of the patient recovered and subsequently the 
1 level of CEA decreased. This result indicated that activity of NK cells might influence

2 the efficacy of trastuzumab.

3 Capecitabine is enzymatically converted to 5-fluorouracil in the tumor by thymidine

4 phosphorylase (TP) [14]. We previously reported that docetaxel-containing regimens

5 modulate TP in primary breast cancer tissues in a neoadjuvant setting [15]. Therefore, it

6 was suggested that the combination of taxane and capecitabine was synergistically

7 effective. Some experiments using human cancer xenografts have indicated this

8 synergic effect and some clinical trials have also suggested that combination therapy of

9 taxane and capecitabine provided favorable effects compared with capecitabine alone

10 [16-17]. In the present case, the tumor responded to combination therapy of trastuzumab,

11 docetaxel, and doxifluridine as a first-line therapy after recurrence. Furthermore, the

combination therapy of paclitaxel and capecitabine was also effective in reducing re-growth of the tumor after induction of activated NK cell injection and trastuzumab.

14 Some reports have also shown that taxanes increased NK cell cytotoxicity. Paclitaxel induced mRNA and protein production of perforin and the activation of nuclear factor- $\kappa \mathrm{B}(\mathrm{NF}-\kappa \mathrm{B})$ in NK cells in vitro [18]. In a taxane treatment group, NK cell cytotoxicity was $39 \%$ higher than that in a non-taxane treatment group [19].

18 Furthermore, several studies have indicated that hyperthermia therapy may increase NK 
1 cell activity [20]. Although paclitaxel and hyperthermia might modulate the activity of

2 NK cells, the relation between the modulation and the treatment response is still unclear.

3 In addition to downregulation of NK cell activity, various other mechanisms such as

$4 \quad$ PTEN and phosphoinositol kinase abnormalities have been suggested to explain

5 trastuzumab resistance $[21,22]$. Therefore knowing the individual mechanism of

6 resistance to anti-HER2 therapy such as trastuzumab or lapatinib is warranted to

7 maximize the effect of anti-HER2 therapy.

8 Interestingly, although this patient was resistant to anti-HER2 therapy and showed an

9 extremely low level of NK cell activity before NK cell injection therapy, NK cell

10 activity increased and response was obtained after the patient received the combined

11 treatment with highly purified and well activated NK cells and trastuzumab.

12 Furthermore, adding TP-inducible chemotherapy and TP-targeting chemotherapy to the treatment yielded an objective response. Our case report indicates that multidisciplinary therapy, including an immunological approach, might be a breakthrough to refractory metastasis. 
1

2

\section{References :}

1. Thor AD, Liu S, Edgerton S, Moore D 2nd, Kasowitz KM, Benz CC, et al. Activation (tyrosine phosphorylation) of ErbB-2 (HER-2/neu): a study of incidence and correlation with outcome in breast cancer. J Clin Oncol 2000; 18: 3230-9.

2. Slamon DJ, Leyland-Jones B, Shak S, Fuchs H, Paton V, Bajamonde A, et al. Use of chemotherapy plus a monoclonal antibody against HER2 for metastatic breast cancer that overexpresses HER2. N Engl J Med 2001; 344: 783-92.

3. Piccart-Gebhart MJ, Procter M, Leyland-Jones B, Goldhirsch A, Untch M, Smith I, et al. Trastuzumab after adjuvant chemotherapy in HER2-positive breast cancer. $\mathrm{N}$ Engl J Med. 2005; 353: 1659-72.

4. Romond EH, Perez EA, Bryant J, Suman VJ, Geyer CE Jr, Davidson NE, et al. Trastuzumab plus adjuvant chemotherapy for operable HER2-positive breast cancer. N Engl J Med 2005; 353: 1673-84.

5. Clynes RA, Towers TL, Presta LG, Ravetch JV. Inhibitory Fc receptors modulate in vivo cytoxicity against tumor targets. Nat Med 2000; 6: 443-6.

6. Gennari R, Menard S, Fagnoni F, Ponchio L, Scelsi M, Tagliabue E, et al. Pilot study of the mechanism of action of preoperative trastuzumab in patients with primary operable breast tumors overexpressing HER2. Clin Cancer Res. 2004 ; 10: 
$1 \quad 5650-5$

2 7. Suzuki E, Niwa R, Saji S, Muta M, Hirose M, Iida S, et al. A nonfucosylated anti-HER2 antibody augments antibody-dependent cellular cytotoxicity in breast cancer patients. Clin Cancer Res 2007 ; 13: 1875-82.

8. Leibson PJ. Signal transduction during natural killer cell activation: inside the mind of a killer. Immunity 1997; 6: 655-61.

7 9. Terunuma H, Deng X, Dewan Z, Fujimoto S, Yamamoto N. Potential role of NK cells in the induction of immune responses: Implications for NK cell-based immunotherapy for cancers and viral infections. Int Rev immunol 2008; 27: 93-110.

10. Dewan MZ, Terunuma H, Takada M, Tanaka Y, Abe H, Sata T, et al. Role of natural killer cells in hormone-independent rapid tumor formation and spontaneous metastasis of breast cancer cells in vivo. Breast Cancer Res Treat 2007; 104: 267-75.. of the NKG2D haplotypes associated with natural cytotoxic activity of peripheral blood lymphocytes and cancer immunosurveillance. Cancer Res. 2006 ; 66: 563-70. 
1 12. Dewan MZ, Takada M, Terunuma H, Deng X, Ahmed S, Yamamoto N, Toi M.

2 Natural killer activity of peripheral-blood mononuclear cells in breast cancer patients. Biomed Pharmacother. 2009; 63:703-6.

13. Koehl U, Sörensen J, Esser R, Zimmermann S, Grüttner HP, Tonn T, et al. IL-2 activated NK cell immunotherapy of three children after haploidentical stem cell transplantation. Blood Cells Mol Dis 2004; 33: 261-6.

14. Miwa M, Ura M, Nishida M, Sawada N, Ishikawa T, Mori K, et al. Design of a novel oral fluoropyrimidine carbamate, capecitabine, which generates 5-fluorouracil selectively in tumours by enzymes concentrated in human liver and cancer tissue. Eur J Cancer 1998; 34: 1274-1281.

15. Toi M, Bando H, Horiguchi S, Takada M, Kataoka A, Ueno T, et al. Modulation of thymidine phosphorylase by neoadjuvant chemotherapy in primary breast cancer. $\mathrm{Br}$ J Cancer 2004; 90: 2338-2343.

16. Sawada N, Ishikawa T, Fukuse Y, Nishida M, Yoshikubo T, Ishitsuka H. Induction of thymidine phosphorylase activity and enhancement of capecitabine efficacy by taxol/taxotere in human cancer xenografts. Clin Cancer Res 1998; 4: 1013-1019. (platelet-derived endothelial-cell growth factor) in cancer biology and treatment. 
Lancet Oncol 2005; 6: 128-166.

18. Kubo M, Morisaki T, Matsumoto K, Tasaki A, Yamanaka N, Nakashima H, et al. Paclitaxel probably enhances cytotoxicity of natural killer cells against breast carcinoma cells by increasing perforin production. Cancer Immunol Immunother. 2005; 54: 468-76.

19. Carson WE 3rd, Shapiro CL, Crespin TR, Thornton LM, Andersen BL. Cellular Immunity in Breast Cancer Patients Completing Taxane Treatment. Clin Cancer Res 2004; 10: 3401-3409.

20. Terunuma H, Wada A, Deng X, Yasuma Y, Onishi T, Toki A, et al. Mild hyperthermia modulates the relative frequency of lymphocyte cell subpopulations: an increase in a cytolytic NK cell subset and a decrease in a regulatory T cell subset. Thermal Med 2007; 23: 41-47.

21. Nagata Y, Lan KH, Zhou X, Tan M, Esteva FJ, Sahin AA, et al. PTEN activation contributes to tumor inhibition by trastuzumab, and loss of PTEN predicts trastuzumab resistance in patients. Cancer Cell 2004 ; 6: 117-27.

22. Berns K, Horlings HM, Hennessy BT, Madiredjo M, Hijmans EM, Beelen K, et al. A functional genetic approach identifies the PI3K pathway as a major determinant of trastuzumab resistance in breast cancer. Cancer Cell 2007; 12: 395-402. 
3 Conflicts of interest

4 All authors declared they have no financial support that may pose a conflict of interest.

6 Informed consent

$7 \quad$ We obtained consent for publication in print and electronically from the patient's

8 husband.

9

10 Figure legend:

\section{$11 \quad$ Figure 1}

12 This figure shows changes of tumor markers and NK cell activity in the patient during

13 activated NK cell injection therapy. It also shows images from a chest CT scan above

14 the graph. NK cell activity in the patient was extremely low before injection of activated

15 NK cells. However, her NK cell activity increased after activated NK cell injection

16 therapy began. Because of disease progression, we also initiated trastuzumab,

17 capecitabine, and paclitaxel with activated NK cell injection therapy. Then tumor markers became smaller, and the lung metastasis was reduced. 